\title{
A Hematodinium-like dinoflagellate infection of the Norway lobster Nephrops norvegicus: observations on pathology and progression of infection
}

\author{
R. H. Field, P. L. Appleton \\ Division of Environmental and Evolutionary Biology, Graham Kerr Building, University of Glasgow, Glasgow G12 8QQ, \\ Scotland, UK
}

\begin{abstract}
The discovery of a Hematodinium-like dinoflagellate infecting Nephrops norvegicus has led to a pathological investigation into the effects on the host and the apparent progression of the disease syndrome. The parasite is systemic, invading the haemocoel and the connective tissues of most organs via the haemal spaces. An increase in the combined number of parasites and haemocytes in the haemolymph was due to an increase in the relative proportion of dinoflagellates and suggested a reduction in numbers of haemocytes. These parameters did not correlate directly with severity. Comparison of the level to which tissues were invaded and the relationship between haemocyte and parasite numbers in the haemolymph suggests that at least some organs may be invaded very early in infection, if not before parasites enter the ohaemolymph. There was evidence of host cellular defence reactions, in the form of haemocyte encapsulations in the gills and heart, and phagocytosis of dinoflagellates by the fixed phagocytes of the hepatopancreas
\end{abstract}

KEY WORDS: Nephrops norvegicus - Hematodinium spp. Parasitic dinoflagellate - Crustacea Pathology

\section{INTRODUCTION}

In recent years, individuals of the commercially important species Nephrops norvegicus (L.), caught on grounds around the west coast of Scotland have been observed to be infected by a parasitic dinoflagellate of the botanical order Syndiniales (Field et al. 1992). In particular, this organism resembles Hematodinium spp., first reported in Carcinus maenas and Liocarcinus depurator by Chatton \& Poisson (1931), and other similar types of parasitic dinoflagellate reported recently in an increasing number of crustaceans over a wide geographic range [Callinectes sapidus in the eastern Atlantic (Newman \& Johnson 1975), several species of benthic amphipod (Johnson 1986), Cancer irroratus, C. borealis and Ovalipes ocellatus (Maclean \& Ruddell 1978) in the western Atlantic, Necora puber and Cancer pagurus on the northern coast of France and the west coast of Scotland (Latrouite et al. 1988, Wilhelm \& Boulo 1988), Chionoecetes bairdi and C. opilio in Alaska, USA (Meyers et al. 1987, 1990, Meyers 1990, 1990, Eaton et al. 1991, Love et al. 1993), and Portunus pelagicus (Shields 1992) and Trapezia sp. (Hudson et al. 1992) in Australia].
Field (1992) and Field et al. (1992) have described preliminary investigations into the pathology and epizootiology of Hematodinium-like infection of Nephrops norvegicus. Following several years of high infection prevalences, catches of $N$. norvegicus, and in particular infected individuals, have been poor. In view of the commercial importance of $N$. norvegicus, and the implication from previous work that infection may be leading to significant mortalities, further research was instigated. Despite the paucity of infected material, reported here are further investigations into the pathology of infection and the course of the disease, undertaken in conjunction with investigations into the in vitro culture of the organism and its life cycle (Vickerman et al. 1993).

Diagnosis of infection and determination of severity were made by pleopod examination as described by Field et al. (1992) (see Fig. 1). This technique estimates the relative degree of parasite aggregation beneath the cuticle of the pleopods (and presumably throughout the haemocoel), and makes the premise that as infection progresses the number of parasitic cells, and hence the thickness of the aggregation layer in the 
pleopod, increases. Field et al. (1992) conducted some counts of haemocytes and parasites together to investigate this hypothesis and to assess its potential as a field diagnostic method for infection and severity. We have now conducted combined parasite and haemocyte counts in fresh haemolymph and determined the relative proportions of haemocytes and parasites in stained haemolymph smears, from both apparently uninfected and infected lobsters, to assess the accuracy of this technique in disease and severity diagnosis. Since individuals examined in the pathological investigation were assigned an infection status by this method, it is now possible to relate haemolymph parasite numbers and tissue changes. In this way it has been possible to determine whether increasing parasite numbers in the haenoiymph aciualiy ieflect the progression of infection, or are merely the result of variation between individual infections.

\section{MATERIALS AND METHODS}

Experimental lobsters. Nephrops norvegicus were caught by trawling on grounds around the Isle of Cumbrae, Clyde Sea area, Scotland, and transported to the Zoology Department, University of Glasgow, where they were maintained in well-aerated sea water for up to $5 \mathrm{~d}$. The aquarium water temperature ranged between 10 and $13^{\circ} \mathrm{C}$ and the salinity between 33 and $34 \%$. Lobsters were fed ad libitum on squid and mussel flesh. All lobsters were in intermoult as defined by the moult staging technique of Aiken (1980). Diagnosis of infection was made by the pleopod assessment method of Field et al. (1992) (Fig. 1).

Counts of haemocytes and dinoflagellate parasites. After assessment of infection severity by pleopod examination, counts were performed of numbers, in fresh haemolymph, of haemocytes and parasites together in 28 infected and uninfected Nephrops norvegicus, by the method given in Field et al. (1992), based on that of Stewart et al. (1967). For statistical analysis, these counts were combined with those reported in Field et al. (1992), since the protocols employed were identical.
Since it was not possible to reliably distinguish between parasites and haemocytes in fresh haemolymph, haemolymph smears were made from an additional 89 infected and uninfected lobsters (again after pleopod examination) as follows. Haemolymph was withdrawn directly from the haemocoel into a disposable syringe containing chilled $5 \%$ formalin in sea water $(33 \%)$, in a ratio of approximately $1: 1$, from the base of a fifth pereiopod. After 5 to $10 \mathrm{~min}$ fixation, samples were gently agitated to re-suspend cells and a small drop of each was smeared on a clean glass slide. Smears were allowed to dry thoroughly, post-fixed in methanol and stained with a $0.2 \% \mathrm{w} / \mathrm{v}$ solution of Leishman's stain (BDH Chemicals Ltd, Poole, England). Each smear was examined at $\times 400$ magnification, and the relative niumbers of host hâemocytes and dinoflagcllates from a total of 200 cells were counted. From these counts the number of parasites was expressed as a percentage of the total of both haemocytes and dinoflagellates together in the haemolymph of each lobster.

Light and electron microscopy. Major tissues and organs were dissected from a total of 29 Nephrops norvegicus, previously staged by pleopod examination. Of these, 9 were apparently uninfected, 5 showed stage I infection, 5 stage II, 5 stage III and 5 stage IV. The organs and tissues removed were hepatopancreas. antennal gland, midgut, abdominal muscle, haemopoietic tissue, heart, gills, and, in some cases, brain and eye/eyestalk. Prior to dissection, lobsters were narcotised in ice for about $1 \mathrm{~h}$. Immediately upon removal, tissue samples for histopathology were fixed in Helly's mercuric chloride fixative (Johnson 1980) and embedded in paraffin wax. Thick sections $(6 \mu \mathrm{m})$ were treated with Lugol's iodine solution to remove mercury, and stained with haematoxylin and eosin (H\&E).

Tissues removed for electron microscopy were fixed in $1 \%$ glutaraldehyde, $2 \%$ paraformaldehyde in $0.1 \mathrm{M}$ phosphate buffer, pH 7.4 with $2 \%$ sucrose and $1.5 \%$ sodium chloride for $2 \mathrm{~h}$ at room temperature. Specimens were then rinsed in $0.1 \mathrm{M}$ phosphate buffer with $4 \%$ sucrose, then post-fixed in $1 \%$ osmium tetroxide in phosphate buffer for $1 \mathrm{~h}$. Specimens were washed in several changes of distilled water and block stained in $0.5 \%$ aqueous uranyl acetate for $1 \mathrm{~h}$. After dehydrating



Fig. 1. Nephrops norvegicus. Light micrographs showing the appearance of pleopods of healthy and dinoflagellate-infected lobsters. The density of the layer of aggre. gated haemocytes and parasites beneath the cuticle indicates the severity of infection on an arbitrary scale from I to IV 0: uninfected, I: slight infection; IV heavy infection. Scale bar $=0.5 \mathrm{~mm}$ 
through an ethanol series specimens were embedded in Spurr resin (Spurr 1969), using propylene oxide as a transitional solvent.

Thick sections $(1 \mu \mathrm{m})$ for light microscopy were stained with $1 \%$ toluidine blue. Suitable areas of tissue were selected and thin sections were cut and mounted on uncoated 300 mesh copper/palladium grids and stained with uranyl acetate (methanolic) and lead citrate.

Thin sections were examined in a Zeiss 902 transmission electron microscope operating at $80 \mathrm{kV}$.

\section{RESULTS}

\section{Numbers of haemocytes and dinoflagellate parasites} in the haemolymph

Table 1 shows the results of the counts of haemocytes and parasites together performed on haemolymph from staged Nephrops norvegicus. These results indicate that there was an increase in the total number of haemocytes and dinoflagellates in the haemolymph of infected $N$. norvegicus. This increase was significant only in individuals staged at III and IV. The increase was due to the higher proportion of dinoflagellates within the haemolymph (Table 2). Stage I individuals showed a slight increase above stage 0 lobsters, but stage II, III and IV individuals showed a further significant rise above this. Although all those lobsters placed in stage 0 were diagnosed as uninfected by pleopod examination a small number were misdiagnosed. Three apparently uninfected lobsters were found to have dinoflagellate parasites in their haemolymph when smears were examined. This discrepancy accounts for the above zero percentage of dinoflagellate parasites in group 0 . Three uninfected lobsters were also misdiagnosed as infected stage I, since their smears contained no detectable parasites.

Table 1. Nephrops norvegicus. Variation of the combined count of haemocytes and parasites in the haemolymph (combined count) in relation to severity of infection as determined by pleopod examination. "Significantly higher than the previous stage, $p<0.005$ (1-way ANOVA). (This table incorporates data from Field et al. 1992)

\begin{tabular}{|c|c|c|c|}
\hline \multirow[t]{2}{*}{$\begin{array}{c}\text { Pleopod } \\
\text { infection stage }\end{array}$} & \multirow[t]{2}{*}{$\begin{array}{l}\text { No. of } \\
\text { lobsters }\end{array}$} & \multicolumn{2}{|c|}{$\begin{array}{l}\text { Combined count } \\
\left(\times 10^{4} \mathrm{~mm}^{-3}\right)\end{array}$} \\
\hline & & Mean & $\mathrm{SD}$ \\
\hline 0 & 20 & 1.117 & 0.626 \\
\hline I & 20 & 1.247 & 0.815 \\
\hline II & 17 & 1.926 & 1.248 \\
\hline III & 10 & 6.937 & $5.304^{\circ}$ \\
\hline IV & 7 & 8.305 & $7.332^{\circ}$ \\
\hline
\end{tabular}

Table 2. Nephrops norvegicus. Variation in percentage dinoflagellates in the haemolymph in relation to severity of infection as determined by pleopod examination. - Significantly higher than the previous stage, $\mathrm{p}<0.005$ (1-way ANOVA)

$\left.\begin{array}{|cccc|}\hline \begin{array}{c}\text { Pleopod } \\ \text { infection stage }\end{array} & \begin{array}{c}\text { No. of } \\ \text { lobsters }\end{array} & \multicolumn{2}{c|}{\text { \% Dinoflagellates }} \\ & & & \mathrm{SD} \\ \hline 0 & 45 & 0.10 & 1.8 \\ \text { I } & 17 & 19.65 & 11.22 \\ \text { II } & 14 & 70.69 & 11.34 \\ \text { III } & 8 & 75.74 & 18.90 \\ \text { IV } & 5 & 97.07 & 0.09\end{array}\right\}$.

\section{Pathology and electron microscopy}

The initial report of this disease syndrome (Field et al. 1992) recognised 2 dinoflagellate cell forms in Nephrops norvegicus, uninucleate and multinucleate/plasmodial cells in the haemolymph and vermiform cells attached in the tissues. Since publication of this work, we have made much progress in the in vitro culture and study of the life cycle of this organism, revealing a more complex range of developmental forms (Vickerman et al. 1993) comprising both filamentous and network syncytia, uninucleate and multinucleate/plasmodial cells, and 2 types of biflagellate motile dinospores.

During the current study we identified 4 separate parasite morphologies within Nephrops norvegicus. Filamentous syncytia (see Fig. 3), sometimes radiating from a central mass, were attached to host tissue bounding haemal spaces and lumina in several organs. These were multinucleate, individual filaments containing up to 5 nuclei. Filament nuclei contained the prominent condensed chromosomes typical of the dinoflagellate dinokaryon (see Figs. $3 \& 13$ ). This parasite form corresponds to the vermiform type described by Field et al. (1992), and resembles the filamentous syncytia observed in vitro by Vickerman et al. (1993). A separate network syncytial form was observed, ramifying between muscle fibres in abdominal muscle (see Fig. 12) and heart, which may correspond to the network form described by Vickerman et al. (1993).

\section{Hepatopancreas}

In infected individuals, the spacing between hepatopancreatic tubules was much enlarged compared with that of uninfected lobsters (Fig. 2). This was sometimes seen as an artefact of dissection and fixation, even in uninfected lobsters, but tubule separation increased with infection severity. The hepatopancreas of infected individuals was difficult to 


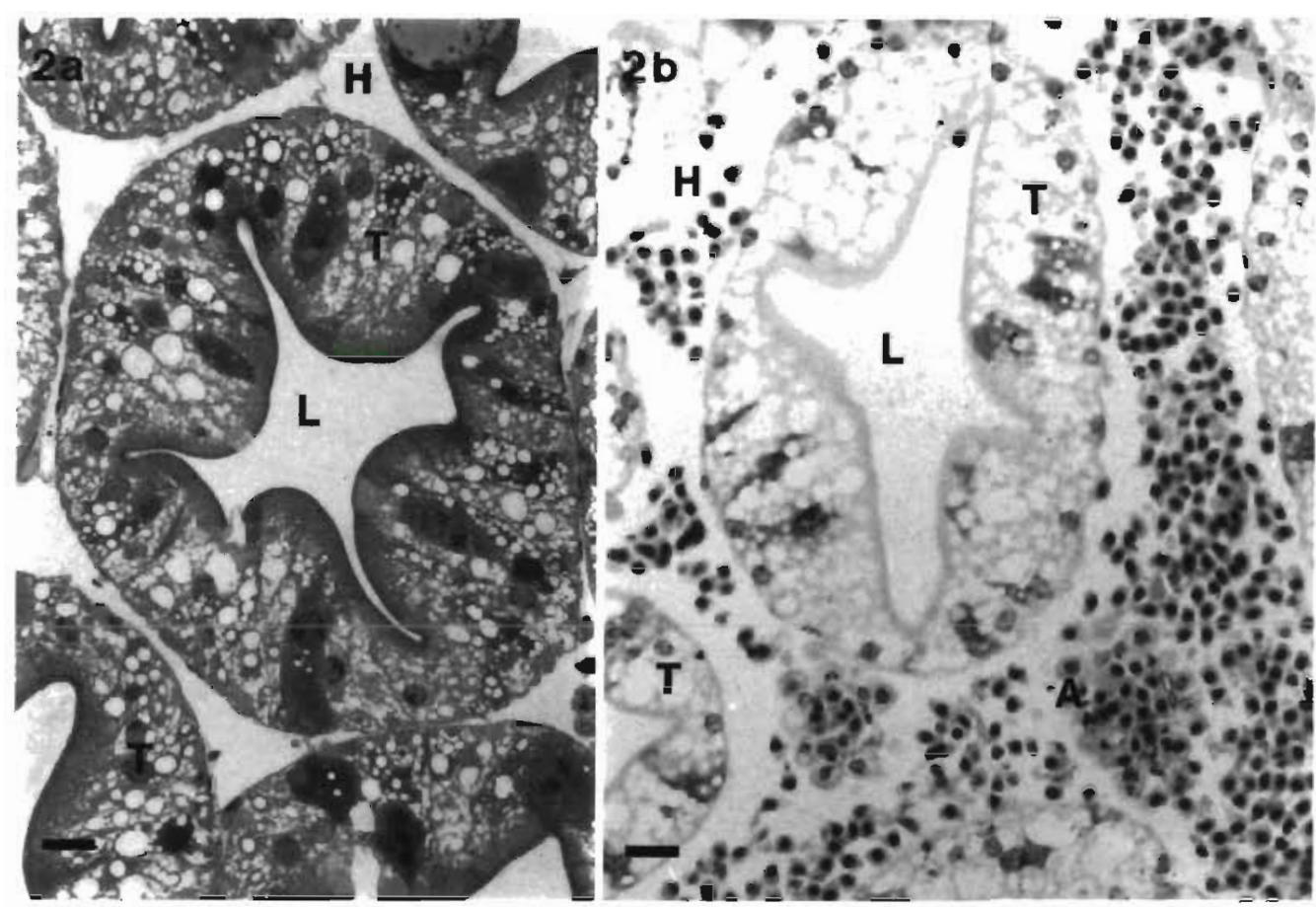

Fig. 2. Nephrops norvegicus. Light micrographs showing the enlargement of spacing between hepatopancreatic tubules in dinoflagellate-infected lobsters. (a) Hepatopancreas of uninfected individual. Toluidine blue. (b) Hepatopancreas of stage IV infected individual, showing increased spacing between the tubules, and the concurrent presence of many uninucleate parasites. $\mathrm{H}$ : haemal sinus; L: lumen of tubule; $\mathrm{T}$ : tubule epithelium; A: hepatopancreatic arteriole. H\&E. Scale bars $=20 \mu \mathrm{m}$

remove because of its almost liquid state. Enlarged spaces within the hepatopancreatic haemal sinus were found to contain large numbers of uninucleate (and occasionally binucleate) parasites, but haemocytes were rarely seen. Occasionally, filamentous syncytia were seen in heavily infected lobsters, attached to the outside of tubules (Fig. 3). Tubule damage in the heavier infections was more profound, involving not only vacuolation of epithelial cells (Figs. $2 \& 3$ ) but the breach of tubule walls, as indicated by the presence of uninucleate parasites within the lumina of tubules in both stage III and stage IV lobsters (Fig. 4).

Activity of the fixed phagocytes surrounding the hepatic arterioles was observed in infected lobsters of all stages, as indicated by the hypertrophied state of these cells (Fig. 5) and the presence of an interrupted layer (Johnson 1987) (Fig. 6). Evidence was seen of retention of parasites in the extracellular space between the interrupted layer and the fixed phagocytes. The majority of dinoflagellates associated with fixed phagocytes were retained in this manner. Phagocytosis was also observed, but less often, evidenced by the form of phagosomes containing degenerative parasite material (Fig. 6). Fixed phagocytes containing such phagosomes were often necrotic. Extracellular spaces contained normal dinoflagellates and parasite debris (Fig. 6).

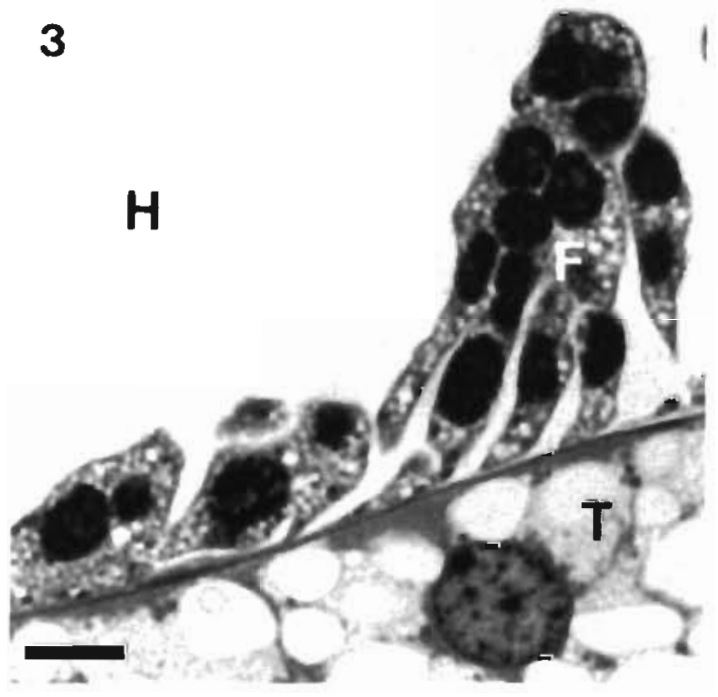

Fig. 3. Nephrops norvegicus. Light micrograph showing filamentous dinoflagellate syncytium attached to the outer wall of a hepatopancreatic tubule of a stage III infected lobster. $\mathrm{H}$ : haemal sinus of hepatopancreas; $\mathrm{F}$ parasite syncytium; $\mathrm{T}$. epithelial cell of hepatopancreatic tubule. Tolundine blue. Scale bar $=15 \mu \mathrm{m}$ 


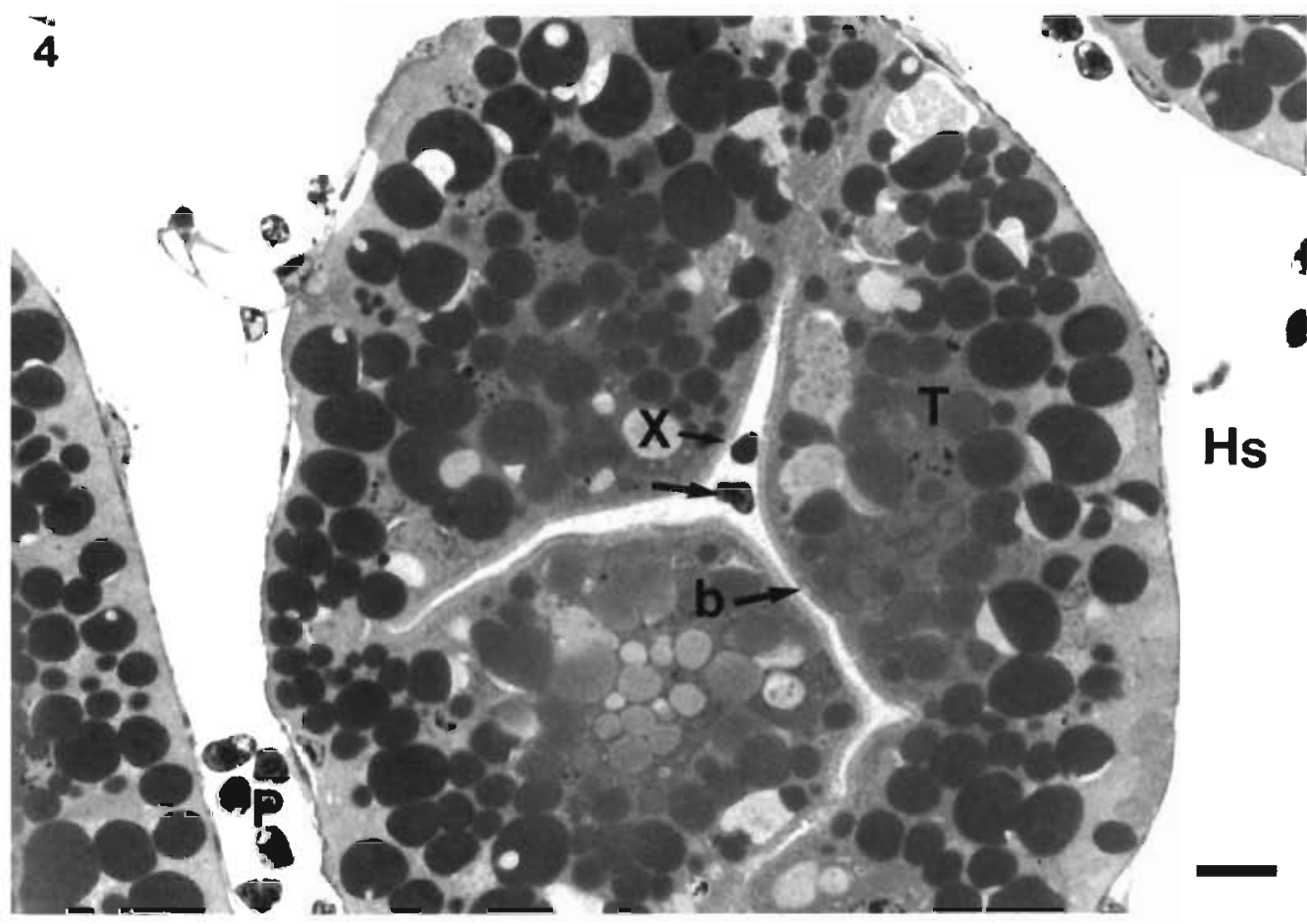

Fig. 4. Nephrops norvegicus. Light micrograph showing the presence of a dinoflagellate within the lumen of a hepatopancreatic tubule of a stage IV infected individual. Note also the presence of flagellate spores in the haemal spaces surrounding the tubules, and a 'secretory packet' (Johnson 1980) in the tubule lumen, possibly a shed 'B'-cell. T: tubule epithelium; b: brush border of epithelial cells; Hs: haemal sinus of hepatopancreas; X: 'secretory packet'; P: biflagellate spores of the parasite; arrow: dinoflagellate within tubule lumen. Toluidine blue. Scale bar $=20 \mu \mathrm{m}$

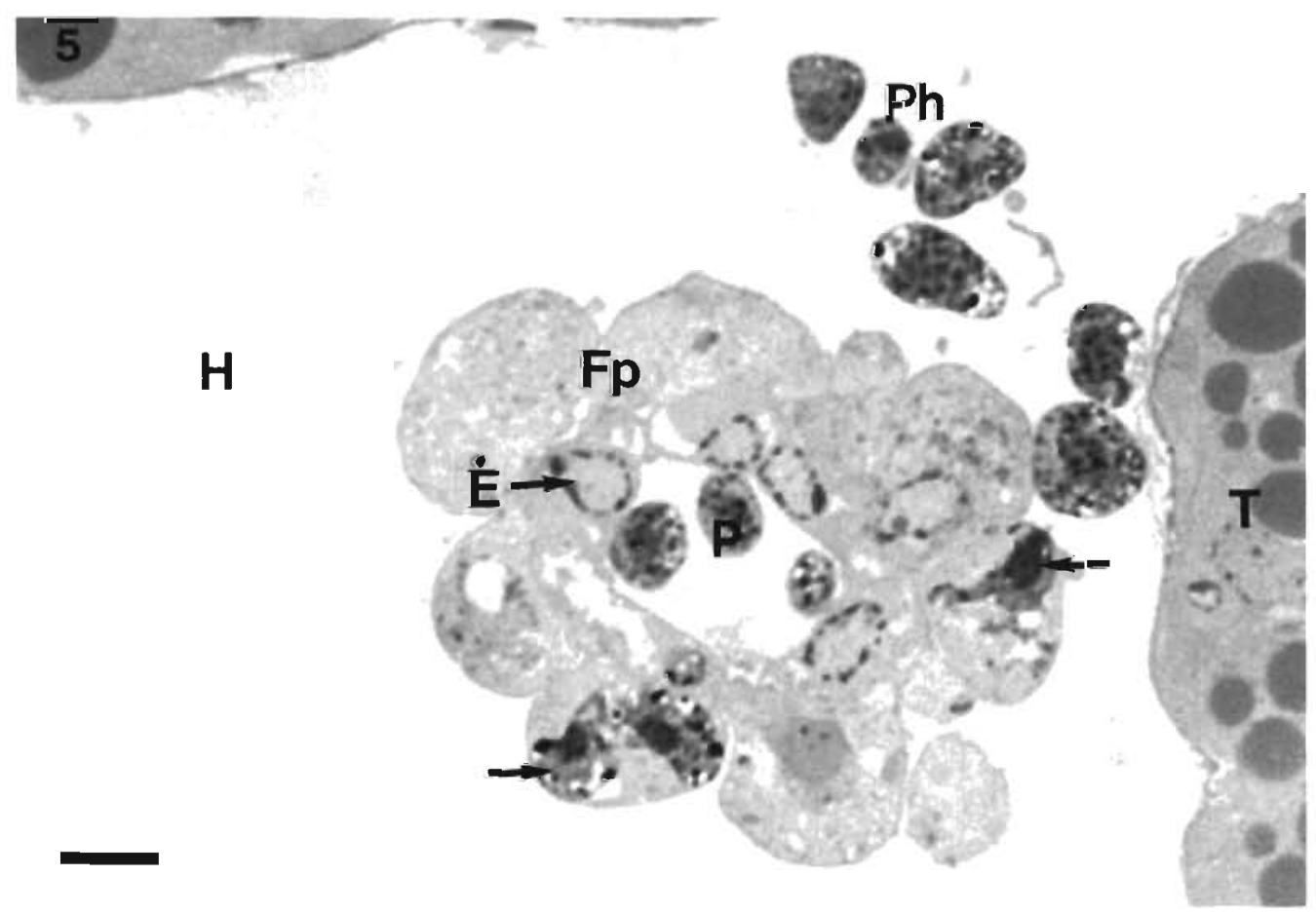

Fig. 5. Nephrops norvegicus. Light micrograph showing fixed phagocytes surrounding an hepatic arteriole in a stage IV infected lobster. Note the dinoflagellates associated with 2 fixed phagocytes (arrows). Ph: parasites in hepatopancreatic haemal sinus; T: hepatopancreatic tubule; Fp: fixed phagocytes; E: endothelium of arteriole; P: parasites within lumen of arteriole. Toluidine blue. Scale bar $=10 \mu \mathrm{m}$ 




Fig. 6. Nephrops norvegicus. Transmission electron micrograph showing detail of a dinoflagellate associated with an hepatopancreatic fixed phagocyte of a stage IV infected lobster. Note the vesicular cytoplasm and the interrupted layer surrounding the fixed phagocyte, and the granular nature of the cytoplasm of the parasite. I: interrupted layer; Hs: haemal sinus of hepatopancreas; Dn: nucleus of dinoflagellate; Dc: cytoplasm of dinoflagellate; Pn: nucleus of adjacent phagocyte Pc: $_{\text {cytoplasm of }}$ fixed phagocyte; Pp: phagosomes. Scale bar $=2.5 \mu \mathrm{m}$

\section{Antennal gland}

The structure of the antennal glands of infected Nephrops norvegicus was largely unaffected in all but the most heavily infected individuals, despite the presence of many dinoflagellates within the haemal spaces and connective tissue of the labyrinth and coelomosac, and branches of the antennary artery. As in the hepatopancreas, the majority of the parasites were uninucleate, but filamentous multinucleate stages were also present, especially attached to the basal side of the labyrinthal epithelium (Fig. 7). There was an increase in numbers of attached parasites with increasing infection stage, though even light infections of stage I showed well-established groups of attached parasite syncytia in the labyrinth. The coelomosac epithelium was unchanged, except for the presence of dinoflagellates in the narrow haemal spaces surrounding it. The labyrinthal epithelium showed some vacuolation, and parasites were present in the lumen of the labyrinth itself (Fig. 7), indicating breach of the epithelium. The labyrinthal epithelium of infected and uninfected lobsters showed a high degree of secretory activity when compared to that of the grass shrimp Palaemonetes pugio, which only showed such activity levels after exposure to biocides (Doughtie \& Rao 1983). This activity was evident even in the antennal gland of heavily infected stage IV Nephrops norvegicus, with the apical brush border of cells often showing extruded granular bodies (Fig. 8), similar to those seen in the antennal gland of Astacus sp. (Parry 1960) and P. pugio (Doughtie \& Rao 1983) 


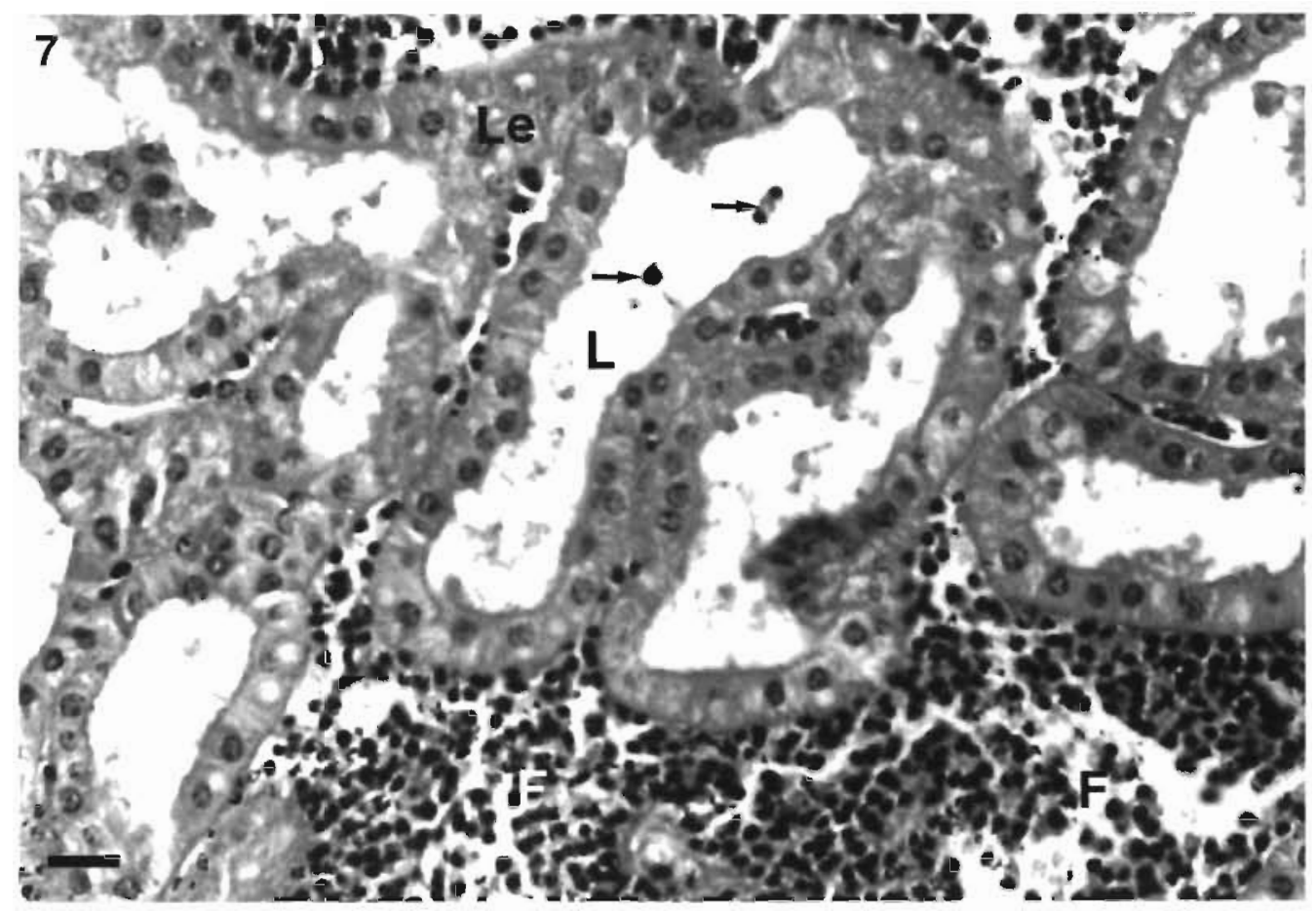

Fig. 7. Nephrops norvegicus. Light micrograph of the labyrinthal epithelium of the antennal gland of a stage III infected individual, showing attachment of filamentous parasite syncytia within the haemal spaces and the presence of dinoflagellates within the lumen of the labyrinth (arrows). Le: labyrinthal epithelium; L: labyrinthal lumen; F: filamentous parasite syncytia. H\&E. Scale bar $=20 \mu \mathrm{m}$

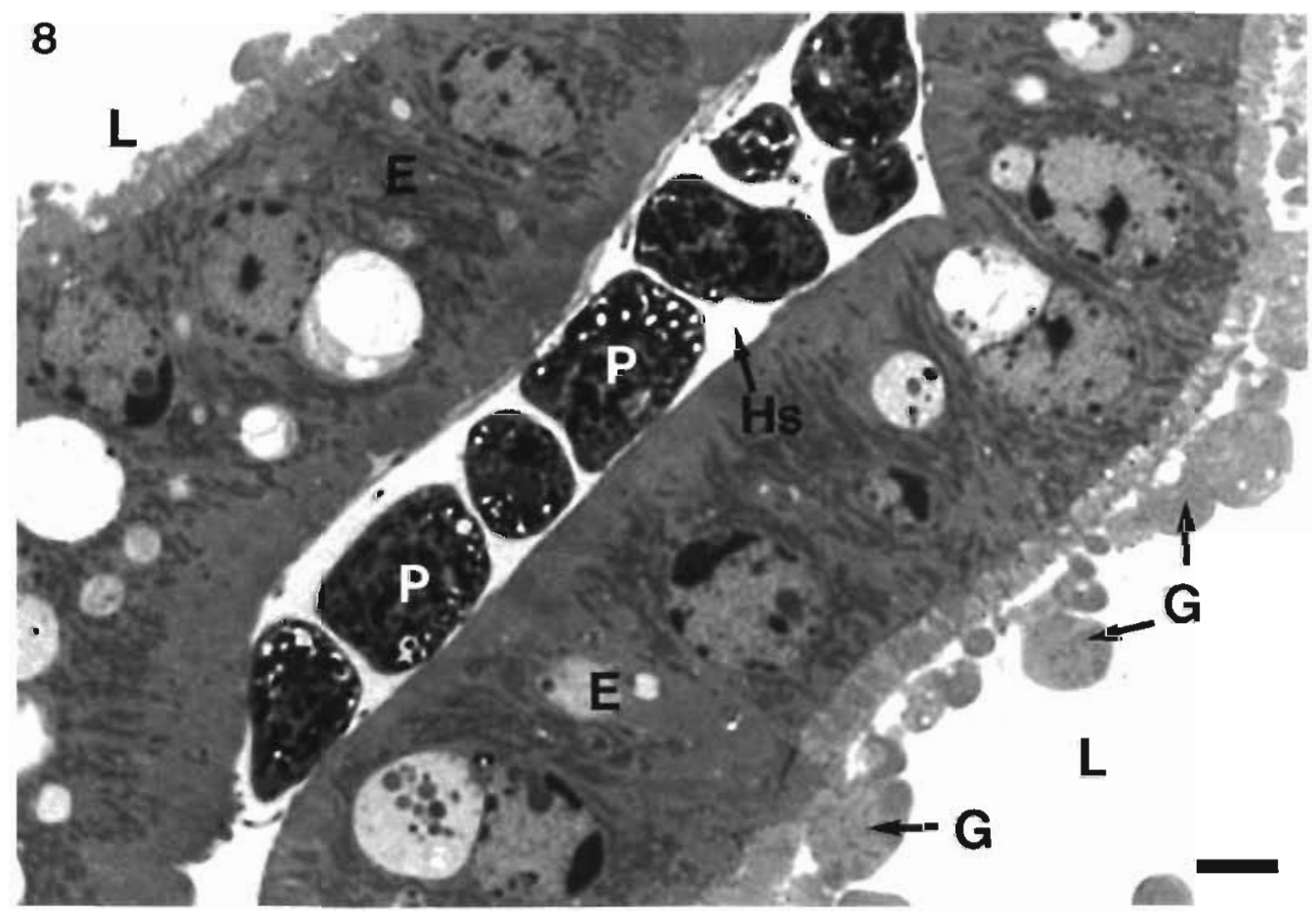

Fig. 8. Nephrops norvegicus. Light micrograph showing detail of the labyrinthal epithelium of a stage IV infected lobster, and the presence of biflagellate spores of the parasite within the haemal spaces. L: labyrinthal lumen; Hs: haemal spaces of labyrinthi P: biflagellate spores of the parasite; E: epithelial cells; G: granular bodies. Toluidine blue. Scale bar $=5 \mu \mathrm{m}$ 
Midgut

Tissue of the midgut exhibited some of the most marked changes as a result of infection by the parasite. The midgut wall of lobsters from all pleopod infection stages showed large-scale infiltration by the dinoflagellates. The connective tissue and muscles of the outer midgut wall had been almost completely replaced by parasites, even in stage I lobsters. The muscle tissue still present in stage I and II individuals (Fig. 9) appeared fragmentary and reduced when compared with that of uninfected lobsters (Fig. 10). The haemal spaces were enlarged and partially occluded by large numbers of attached filamentous parasite syncytia. Few haemocytes were observed in these haemai spaces in infected iobsiers, especiaiiy in stage III and IV individuals. There was limited evidence of a host cellular defence reaction within the gut wall of stage I lobsters, where small numbers of haemocytes were aggregated around dinoflagellates.

Parasites in the midgut wall were predominantly filamentous syncytia, especially in light infections, where uninucleate forms were less apparent. Histologically, the basement membrane and the layers of granular cells underlying it were unaffected by infection. The frequency of occurrence of these granular cells did not seem to correlate with infection. The identity of these granular cells is as yet uncertain, though they resemble granulocytes.

Evidence of any alteration of the midgut epithelium was scant, with both villi and epithelial corrugations still present in stage IV infected lobsters. Lysis and vacuolation of epithelial cells by infection was not readily distinguished from that caused by prefixation artefact. There was also no evidence of parasite invasion of the epithelium or any tissues on the lumen side of the basement membrane. A concurrent gregarine infection, tentatively identified as an eugregarine was found in the midgut lumen of one of the stage IV lobsters (Fig. 11).

\section{Abdominal muscle}

The abdominal muscle of healthy Nephrops norvegicus displayed histologic features typical of crustacean homogeneous fast phasic skeletal muscle. The fibres had a short sarcomere length (2 to $4 \mu \mathrm{m}$ ) and lightly staining nuclei, with peripherally dense chromatin. In general, these features remained unchanged in the abdominal deep muscles of dinoflagellate-infected individuals. In wax-embedded sections parasite invasion of muscle fibres was not apparent, even though free uninucleate parasites were frequently encountered in interstices between muscle fibres in stage I



Fig. 9. Nephrops norvegicus. Light micrograph of the midgut wall of a stage II infected individual showing both attached filamentous syncytia and possibly uninucleate parasites. P: possibly uninucleate parasites; F: filamentous syncytia; M: circular muscle layer of midgut wall; $b$ : basement membrane; $E$ : epithelium; L: lumen. Toluidine blue. Scale bar $=20 \mu \mathrm{m}$ 


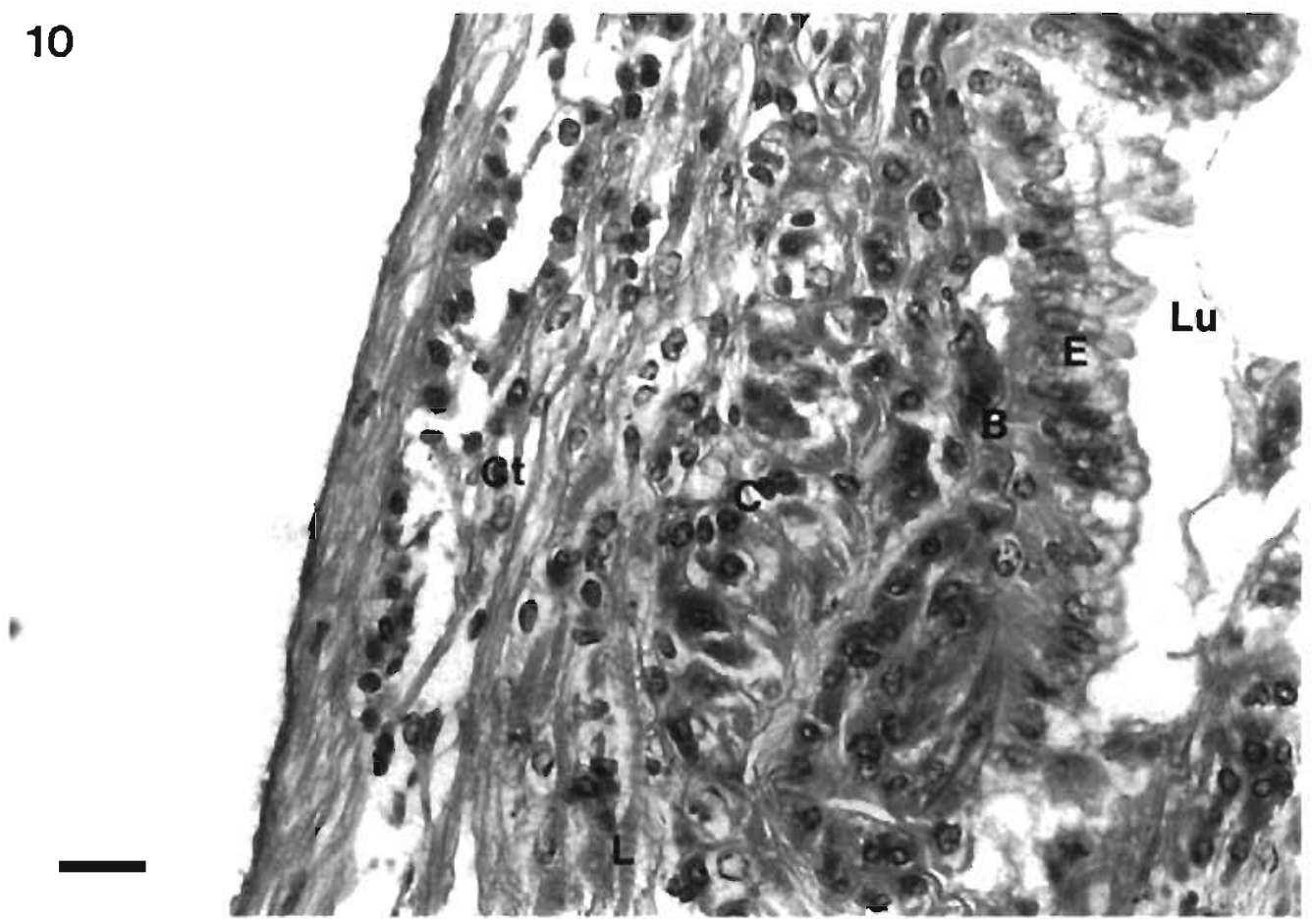

Fig. 10. Nephrops norvegicus. Light micrograph of the midgut wall of an uninfected lobster showing the connective tissue and muscles of the outer wall. Ct: connective tissue; L: longitudinal muscle; C: circular muscle; B: basement membrane; E: epitheiium; Lu: lumen. H\&E. Scale bar $=20 \mu \mathrm{m}$

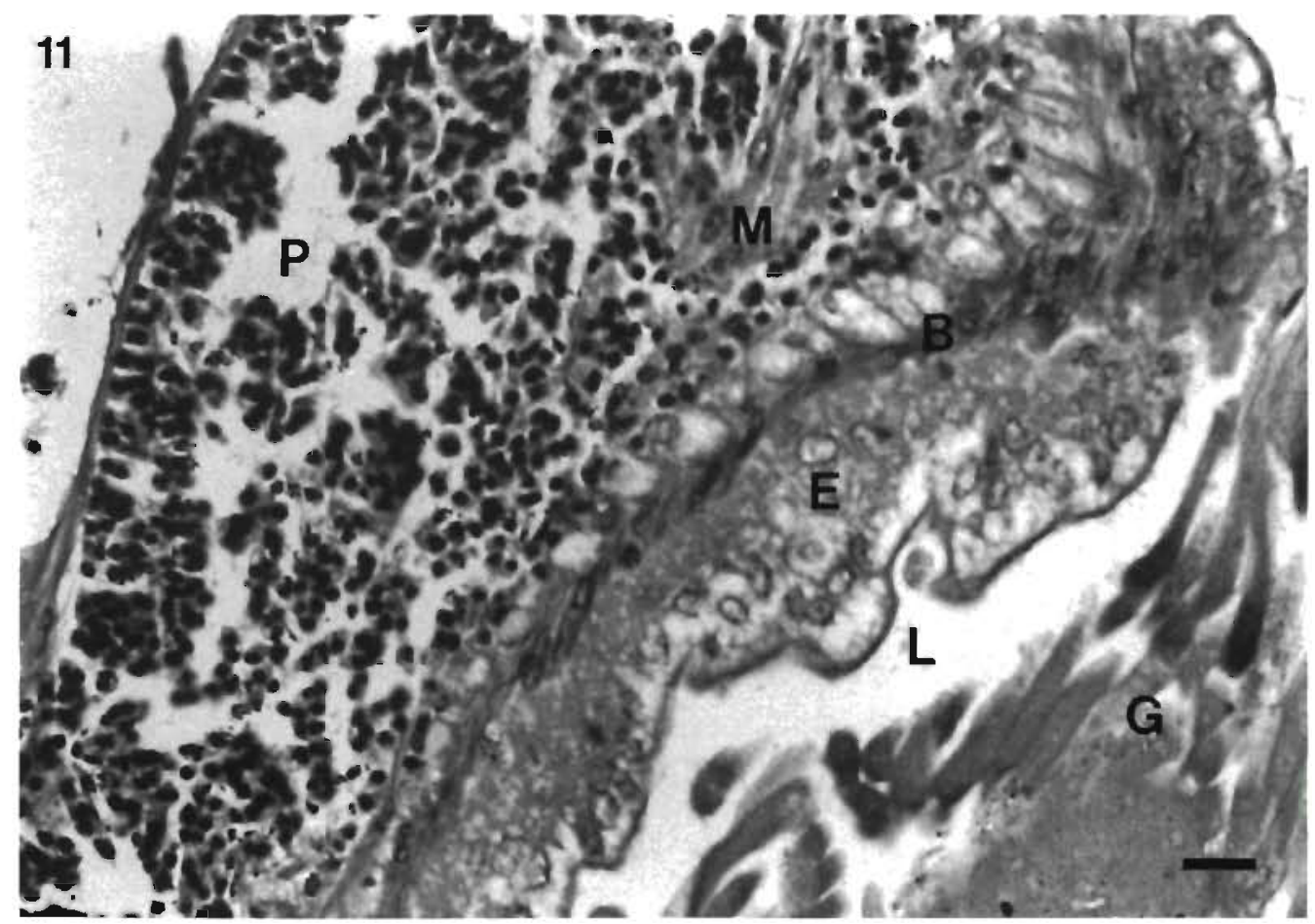

Fig. 11. Nephrops norvegicus. Light micrograph of the midgut wall of a stage III infected lobster showing a simultaneous infection by dinoflagellates and an unidentified gregarine. P: dinoflagellates within the midgut wall; M: muscle layer; B: basement membrane; E: midgut epithelium; L: midgut lumen; G: gregarines within midgut lumen. H\&E. Scale bar $=20 \mu \mathrm{m}$ 
lobsters. The interstitial connective tissues of skeletal muscle remained intact. In stage III and IV lobsters, however, network-like parasite syncytia were present within skeletal muscle interstices (Fig. 12), and connective tissue was reduced. Furthermore, peripheral areas of some fibres were lysed, and uninucleate parasites were also present in the haemal spaces surrounding the fibres. Uninucleate and multinucleate forms of the parasite, like those found in the haemolymph, were often closely associated with the sarcolemma of fibres (Fig. 13).

\section{Haemopoietic tissue}

The haemopoietic tissue of Nephrops norvegicus is a thin sheet of tissue on the dorsal and lateral surfaces of the cardiac stomach (gastric mill) and probably on the ventral floor of the cephalic cavity, adjoining the antennal glands. The haemopoietic tissue of healthy lobsters was difficult to locate, despite the removal and examination of the entire roof of the cardiac stomach with its attendant epithelium and connective tissues. A few nodes were located, but these generally showed little activity, possibly because specimens were dissected in winter, when Johnson (1980) reported haemocyte production to be low in Callinectes sapidus.
In contrast, the haemopoietic tissue of dinoflagellateinfected Nephrops norvegicus showed a dramatic increase in size, evident even to the naked eye during dissection of stage III and IV lobsters. This was due, in part, to a much increased level of haemopoietic activity, with many nodes containing differentiating cells, mitotic figures and what appeared to be stem cells. However, despite this vast increase in both the number and activity of stem cells, very few newly differentiated haemocytes were visible in the haemal spaces surrounding the haemopoietic nodes (Fig. 14). Instead these spaces were filled with many uninucleate and multinucleate dinoflagellates, even in lower level stage I and II infections.

\section{Heart}

The general microscopic structure of the heart of infected individuals remained unchanged in all except the most moribund of stage IV lobsters. There was again invasion of all haemal spaces by the parasite. The lumen, haemal spaces and connective tissue of the myocardium were massively infiltrated mainly by attached filamentous dinoflagellate syncytia, already well established in stage I individuals. Network-like parasite syncytia were also seen to ramify through the interstices of the myo-

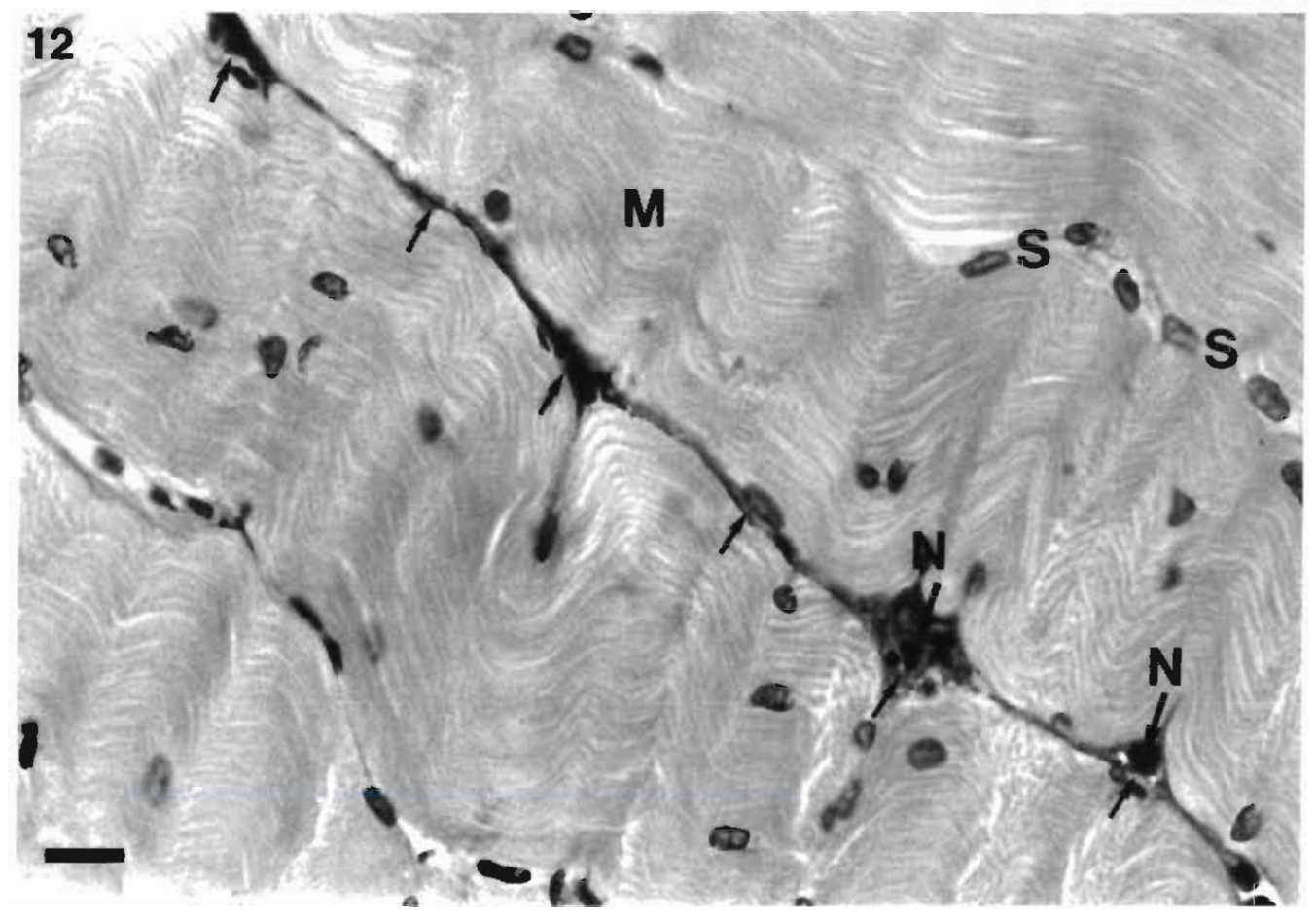

Fig. 12. Nephrops norvegicus. Light micrograph of abdominal muscle of a stage II infected individual showing network-like parasite syncytia within the muscle interstices. $\mathrm{M}$ : abdominal muscle fibres; $\mathrm{N}$ : parasite nuclei; $\mathrm{S}$ : muscle nuclei; arrows: parasite syncytia within muscle interstices. H\&E. Scale bar $=20 \mu \mathrm{m}$ 


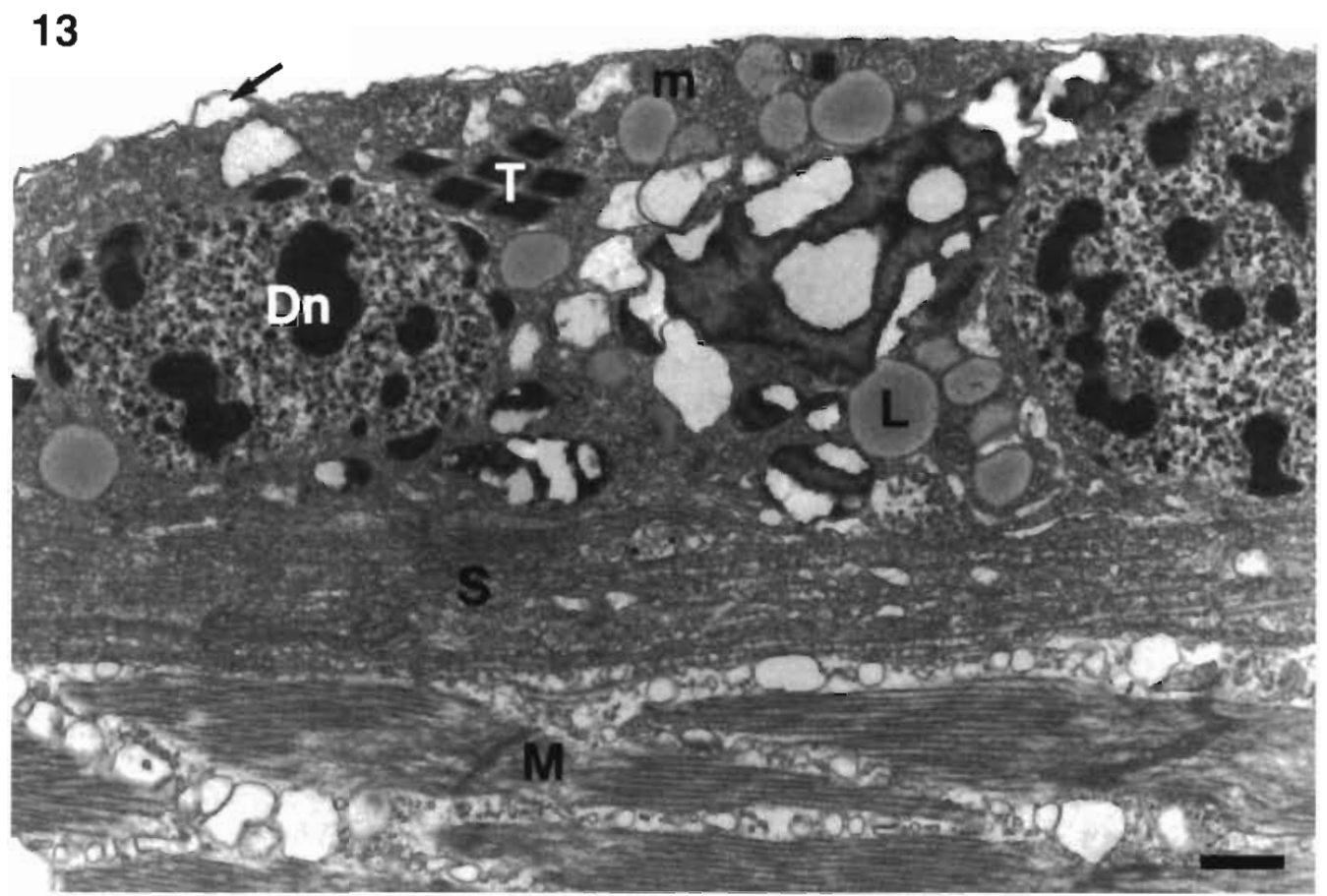

Fig. 13. Nephrops norvegicus. Transmission electron micrograph showing a dinoflagellate associated with the sarcolemmal membrane of an abdominal muscle fibre from a stage IV infected lobster. m: mitochondrion of parasite; T: trichocysts; Dn: dinoflagellate nucleus; L: lipid-like droplet; S: sarcolemma of abdominal muscle fibre; $\mathrm{M}$ : muscle fibre; arrow: amphiesmal alveolus of dinoflagellate plasma membrane. Scale bar $=1 \mu \mathrm{m}$



Fig. 14. Nephrops norvegicus. Light micrograph showing apparently active haemopoietic tissue of a stage IV infected lobster, surrounded by many uninucleate and multinucleate dinoflagellates. N: haemopoietic node; S: probable stem cell; F: mitotic figure; D: differentiating cells; arrow: host haemocyte. Toluidine blue. Scale bar $=20 \mu \mathrm{m}$ 


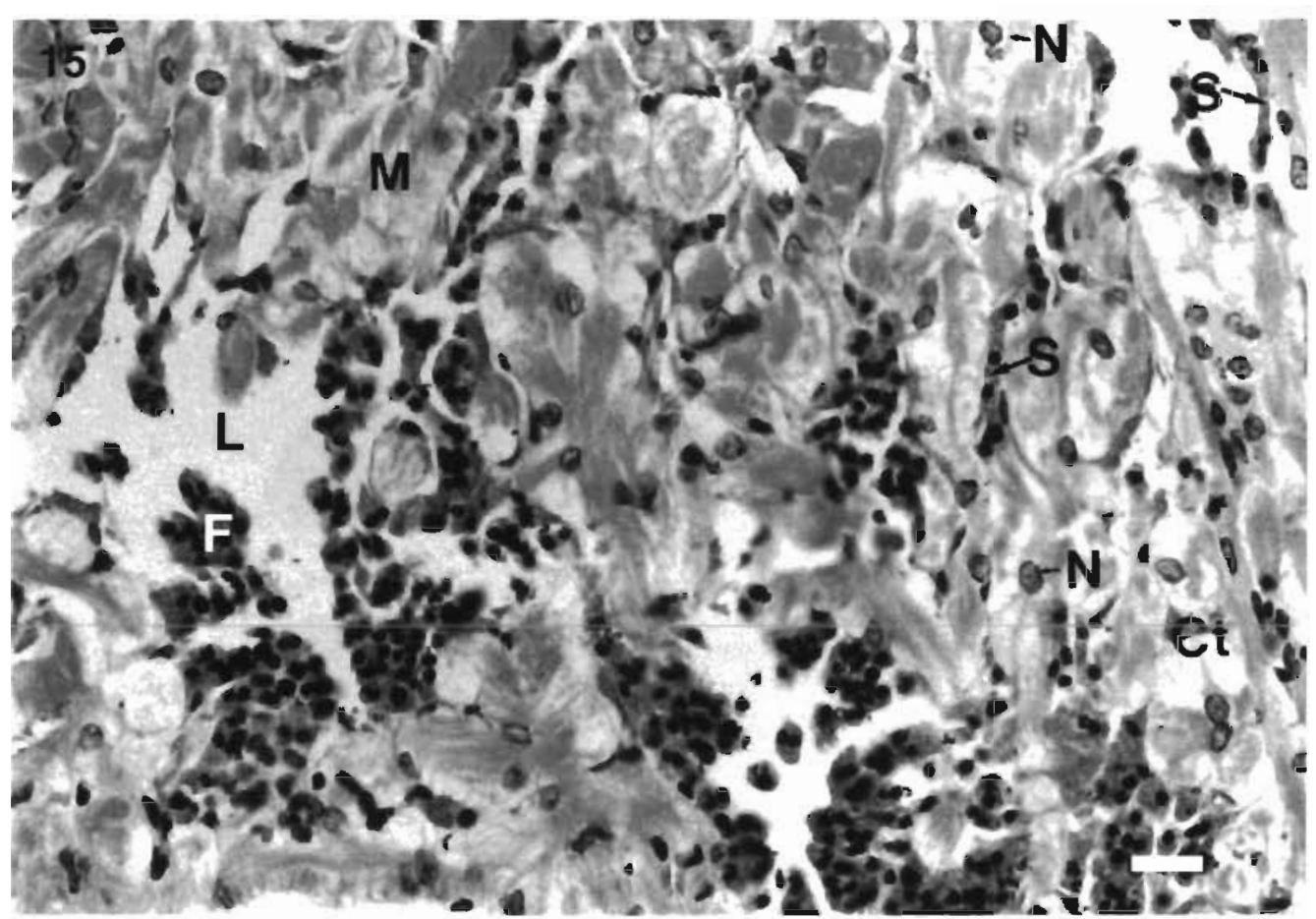

Fig. 15. Nephrops norvegicus. Light micrograph of the myocardium of the heart of a stage II infected individual, showing the presence of both filamentous and network syncytia of parasites attached to myocardial muscle within the lumen. L: lumen of heart; M: myocardial muscle; F: filamentous dinoflagellate syncytia; S: network-like dinoflagellate syncytia; N: myocardial nuclei; $\mathrm{Ct}$ : connective tissue. H\&E. Scale bar $=20 \mu \mathrm{m}$

cardial muscle in all stages (Fig. 15), similar to those in abdominal muscle interstices. Some haemocyte aggregations were seen in the lumen of the hearts of stage I to III individuals. These aggregations were tightly packed and had nuclei of a karyolytic appearance. These resembled haemocyte encapsulations observed in response to bacterial infections in Homarus americanus (Johnson et al. 1981) and Callinectes sapidus (Johnson 1976), and previously reported in Nephrops norvegicus gills (Field et al. 1992), and may represent a degree of host response to parasites, although aggregations have not yet been confirmed as containing dinoflagellates.

\section{Gills}

The major effect on the gills was the occlusion of haemal spaces by large numbers of dinoflagellates. This was more severe in higher infection stages, but still apparent in stage I and II lobsters. Attached parasite syncytia were not observed in this tissue, but evidence of host reaction to infection was seen. Haemocyte aggregations similar to those observed in the lumen of the heart were seen in gill filaments (Field et al. 1992), sometimes apparently blocking them. Aggregations were more frequent in the gills than the heart, but were only seen in the narrower regions of the filaments. Free haemocytes were rare, particularly in those lobsters with gills having large numbers of free parasites.

\section{Other organs}

In brain and eyestalk tissues there were no overt signs of parasite infiltration or tissue change. Parasites were restricted to uninucleate forms in the haemal sinuses and vessels of these tissues.

It should be noted that in some organs (particularly heart and hepatopancreas) the numbers of unattached parasites observed in haemal spaces and lumina may be an under-representation of actual numbers, due to losses during processing for both light and electron microscopy.

\section{DISCUSSION}

The effects of dinoflagellate infection of Nephrops norvegicus are typical of those reported for haemocoelic infections of decapods by both protistans and bacteria of several groups. The general histologic features of tissue change of the digestive and excretory 
organs and of interference with respiratory exchange, haemopoiesis or metabolism (Field 1992) are characteristic of such haemocoelic infections caused by bacteria (Johnson 1976), dinoflagellates (Maclean \& Ruddell 1978, Meyers et al. 1987, Meyers 1990), Chlamydia-like organisms (Sparks et al. 1985) and ciliates (Sparks et al. 1982). However, many protistan and bacterial diseases, such as gaffkemia and the presently reported dinoflagellate infection, may have notable effects on the serum of the haemolymph, as well as on the physiology and metabolism of their hosts. These aspects remain largely un-investigated. More information is available upon the histopathology of infected hosts, on haemocyte changes and responses and on their progenitor, the haemopoietic tissue.

The results presented here confirm that there is an increase in the combined number of haemocytes and parasites in the haemolymph with infection, due to increases in the proportion of dinoflagellates, and that this increases with severity as determined by the pleopod staging method. These increases did not correlate directly with the pleopod staging series; combined haemocyte/parasite counts were not raised significantly above the range of apparently uninfected levels until the pleopod assessment indicated stage III or stage IV infection. At this stage, dinoflagellate parasites comprised over $70 \%$ of the combined haemocyte/ dinoflagellate numbers. This also suggests a reduction in the number of haemocytes in the circulation, coincident with parasite proliferation. The staging technique detects an increase in the severity of haemolymph/ haemocoel infection even in stage I lobsters. However, histopathological evidence suggests that dinoflagellate infection is much more severe than indicated by haemolymph infection alone, and that the pleopod staging method is less sensitive than previously believed. Most major organs and tissues were heavily infiltrated with parasite stages in the stage I lobsters examined, raising the possibility that parasites in the haemolymph originate from earlier tissue forms. These results indicate that the pleopod staging method is relatively reliable as a field method for detecting the presence of dinoflagellates in the haemolymph, but may be less so as an indicator of absolute infection and the involvement of the tissues.

Haemocytopoenia has been noted as a sign of many haemocoelic infections of crustaceans caused by both bacteria and protists. Disappearance of haemocytes from circulation has been noted in gaffkemia of Homarus americanus (Stewart et al. 1969, Johnson et al. 1981), Paranophrys sp. infection of dungeness crabs Cancer magister (Sparks et al. 1982), and Paramoeba perniciosa infections (Johnson 1977) and bacterial infections (Johnson 1976) of blue crabs Callinectes sapidus. Sparks et al. (1982) attribute the haemo- cytopoenia in dungeness crabs infected with ciliates to consumption of haemocytes by the invading cells However, reduction in haemocyte numbers in $P$. perniciosa infections was reported to be the result of host cellular defence reactions, the possible lysis of host cells after phagocytosing parasite cells, and possible disruption of haemopoietic tissue function (Johnson 1977). Similarly, in gaffkaemic lobsters, haemocyte aggregations are widely reported in response to the invading bacteria (Rittenburg et al. 1979, Johnson et al. 1981). It is, therefore, possible that in Nephrops norvegicus infected with dinoflagellates, increased activity in the haemopoietic tissue and the presence of haemocyte aggregations are indications of the initiation of a host reaction to infection. The haemocytes may be removed from circulation by encapsulating dinoflagellates, forming the aggregations observed. The increase in haemopoietic activity may be explained, in part at least, by the time of year at which infected individuals were available. The occurence of lobsters infected with the dinoflagellate is seasonal (Field 1992, Field et al. 1992), occurring in the spring and early summer, a time when large-scale haemocyte production is known to occur in some decapods, e.g. C. sapidus (Johnson 1980). Even stage IV dinoflagellate-infected $N$. norvegicus retain apparently functional fixed phagocytes, but despite this and the increased haemopoietic activity, appear unable to control the parasites. The paucity of haemocytes may be explained by their sequestration into haemocyte capsules and other defence reactions at an early stage of infection. These reactions are apparently overwhelmed by the increasing parasite load. An alternative view is that the host fails to respond due to some action of the parasite.

Another salient feature of the presence of so many invading parasites within the haemocoel is the mechanical disruption they cause to blood circulation. Apart from the hydrostatic effects of this overburden of circulating cells, clogging of blood vessels and sinuses may also occur. This will be particularly so in areas of restricted diameter, such as the smaller capillaries and sinuses, and the haemal spaces within organs. Restriction of blood flow is likely to be further exacerbated within areas where large numbers of filamentous parasite syncytia are attached to host tissues. Clogging may also result from the formation of haemocyte aggregations as part of a host response to infection, as seen in the gill filaments of Nephrops norvegicus, and postulated by Rittenburg et al. (1979) to contribute to tissue hypoxia in gaffkaemic lobsters. The aggregation of haemocytes, and the formation of acellular haemolymph clots in blue crabs Callinectes sapidus in response to bacterial infections, have also been implicated in impeding blood flow through the gills (Johnson 1976). 
As yet there is no irrefutable evidence that this condition is always fatal to infected lobsters (Field et al. 1992), although the systemic nature of the infection and its wide variety of effects upon the host suggest that severe debility and death probably result in many, if not all, cases.

Acknowledgements: This work was conducted with support partly from the Science and Engineering and Research Council (CASE award to R.H.F.) and partly from the Ministry of Agriculture, Fisheries and Food.

\section{LITERATURE CITED}

Aiken DE (1980) Moulting and growth. In: Cobb JS, Phillips BF (eds) The biology and management of lobsters. Vol 1 Academic Press, New York, p 91-163

Chatton E, Poisson R (1931) Sur l' existence, dans le sang des crabs, de peridiniens parasites Hematodinium perezi n.g. n.sp. (Syndinidae). C r séanc Soc biol 105:553-557

Doughtie DG, Rao KR (1983) Ultrastructural and histological study of degenerative changes in the antennal glands, hepatopancreas, and midgut of grass shrimp exposed to two dithiocarbamate biocides. J Invertebr Pathol 41. $281-300$

Eaton WD, Love DC, Botelho C, Meyers TR, Imamura K, Koeneman $T$ (1991) Preliminary results on the seasonality and life cycle of the parasitic dinoflagellate causing bitter crab disease in Alaskan tanner crabs (Chionoecetes bairdi). $\mathrm{J}$ Invertebr Pathol 57:426-434

Field RH (1992) The control of escape behaviour in, and the histopathology of, the Norway lobster, Nephrops norvegicus (L.). PhD thesis, University of Glasgow

Field RH, Chapman CJ, Taylor AC, Neil DM, Vickerman K (1992) Infection of the Norway lobster Nephrops norvegicus by a Hematodinium-like species of dinoflagellate on the west coast of Scotland. Dis aquat Org 13:1-15

Hudson DA, Hudson NB, Shields JD (1992) Infection of Trapezia spp. (Decapoda: Xanthidae) by Hematodinium sp. (Duboscquodinida: Syndinidae): a new family record of infection. J Fish Dis 16:273-276

Johnson PT (1976) Bacterial infection in the blue crab. Callinectes sapidus: course of infection and histopathology. $\mathrm{J}$ Invertebr Pathol 28:25-36

Johnson PT (1977) Paramoebiasis in the blue crab Callinectes sapidus. J Invertebr Pathol 29:308-.320

Johnson PT (1980) Histology of the blue crab, Callinectes sapidus. A model for the Decapoda. Praeger, New York

Johnson PT (1986) Parasites of benthic amphipods: dinoflagellates (Duboscquodinida: Syndinidae). Fish Bull 84: $605-614$

Johnson PT (1987) A review of fixed phagocytes and pinocytotic cells of decapod crustaceans, with remarks on hemocytes Dev Comp Immunol 11:679-704

Johnson PT, Stewart JE, Arie B (1981) Histopathology of Aerococcus viridans var. homari infection (Gaffkemia) in the lobster, Homarus americanus, and a comparison with histological reactions to a Gram-negative species Pseudomonas perolens. J Invertebr Pathol 38:127-148

Latrouste D, Morizur Y, Noël P, Chagot D, Wilhelm G (1988) Mortalité du torteau Cancer pagurus provoquée par le

Responsible Subject Editor: J. E. Stewart, Dartmouth, Nova Scotia, Canada dinoflagelle parasite: Hematodinum sp. Comm Meet int Coun Explor Sea CM-ICES 1988/K:32

Love DC, Rice SD, Moles DA, Eaton WD (1993) Seasonal prevalence and intensity of Bitter Crab dinoflagellate infection and host mortality in Alaskan Tanner crabs Chionoecetes bairdi from Auke Bay, Alaska, USA. Dis aquat Org 15:1-7

Maclean SA, Ruddell CL (1978) Three new crustacean hosts for the parasitic dinoflagellate Hematodinium perezi (Dinoflagellata: Syndinidae). J Parasitol 64:158-160

Meyers TR (1990) Disease of Crustacea. Diseases caused by protistans and metazoans. In: Kinne $O$ (ed) Diseases of marine animals, Vol 3. Biologische Anstalt Helgoland, Hamburg, p 350-389

Meyers TR, Botelho C, Koeneman TM, Short S, Imamura K (1990) Distribution of bitter crab dinoflagellate syndrome in southeast Alaskan tanner crabs Chionoecetes bairdi. Dis aquat Org 9:37-43

Meyers TR. Koeneman TM. Botelho C. Short S (1987) Bitter Crab Disease: a fatal dinoflagellate infection and marketing problem for Alaskan tanner crabs Chionoecetes bairdi. Dis. aquat. Org. 3:195-216

Newman MW, Johnson CA (1975) A disease of blue crabs (Callinectes sapidus) caused by a parasitic dinoflagellate, Hematodinium sp. J Parasitol 61:554-557

Parry G (1960) Excretion. In: Waterman TH (ed) The physiology of Crustacea, Vol 1. Metabolism and growth. Academic Press, New York, p 341-366

Rittenberg JH. Gallagher ML, Bayer RC, Leavitt DF (1979) The effect of Aerococcus viridans var. homari on the oxygen binding capacity of hemocyanin in the American lobster (Homarus americanus). Trans A.m Fish Soc 108:172-177

Shields JD (1992) Parasites and symbionts of the crab Portunus pelagicus, from Moreton Bay, Australia. J Crust Biol $12: 94-100$

Sparks AK, I libbits J, Fegley JC (1982) Observations on the histopathology of a systemic ciliate (Paranophrys sp.?) disease in the dungeness crab Cancer magister. J Invertebr Pathol 39:219-228

Sparks AK, Morado JF, Hawkes JW (1985) A systemic microbial disease in the dungeness crab Cancer magister, caused by a Chlamydia-like organism. J Invertebr Pathol 45:204-217

Spurr AR (1969) A low viscosity epoxy embedding resin for electron microscopy. J Ultrastruct Res 26:31-43

Stewart JE, Arje B, Zwicker BM, Dingle JR (1969) Gaffkemia, a bacterial disease of the lobster, Homarus americanus: effects of the pathogen, Gaffkya homan, on the physiology of the host. Can J Microbiol 15:925-932

Stewart JE, Cornick JW, Dingle JR (1967) An electronic method for counting lobster (Homarus americanus Milne Edwards) hemocytes and the influence of diet on hemocyte numbers and hemolymph proteins. Can J Zool 45 $291-304$

Vickerman K. Appleton PL. Field RH (1993) Cultivation and development in vitro of a parasitic dinoflagellate (Hematodinium sp) from the Norway lobster (Nephrops norvegicus). In: Abstracts of the IX International Congress of Protozoology. German Soclety of Protozoology and German Society of Parasitology, Berlin, p 131

Wilhelm, G. \& Boulo, V (1.988). Infection de l'étrille Liocarcinus puber (L.) par un dinoflagelle parasite de type Hematodinium sp. Comm Meet int Coun Explor Sea CM-ICES 1988/K:41

Manuscript first received: August 24, 1994

Revised version accepted: February 23, 1995 